\title{
The Influence and Value of Network Public Opinion on Public Policy
}

\author{
Liu Yanan \\ School of Marxism, Nanjing Normal University, Nanjing, China
}

\section{Email address:}

1342914626@qq.com

\section{To cite this article:}

Liu Yanan. The Influence and Value of Network Public Opinion on Public Policy. Social Sciences. Vol. 9, No. 4, 2020 , pp. $107-112$. doi: 10.11648/j.ss.20200904.14

Received: June 30, 2020; Accepted: July 10, 2020; Published: July 22, 2020

\begin{abstract}
Internet public opinion is a new way to express public interest in the internet age. At the same time, the birth of the internet has promoted the emergence of "public domain" what Habermas calls, which directly links the public opinion of the internet with public policy. As we all known, scientific, democratic and effective public policy is an indispensable and specific system design and arrangement for modern national public governance, which expresses the public policy perceptionands and attitudes in the public interest to the greatest extent possible. So it is an important component of constructing modern national governance system and an important way to enhance national governance ability. Network public opinion is a new form of expression of social opinion, which coupled with the public tendency towards the network and gradually expresses inganuciatic policy attitude through the network, so its application has become an important way to make China's public policy democratization and scientific.. This kind of network tendency marginalizes the pre-set mainstream expression path in the political system, and causes the thinking about whether the network is "alternative" or "complementary". Therefore, it is necessary to examine the degree of influence of network public opinion on public policy and its value orientation, and then we should give full play to the positive effect of network public opinion, so as to make it a complementary way to the mainstream way of public expression of policy attitude.
\end{abstract}

Keywords: Network Public Opinion, Public Policy, Influence, Value

\section{Introduction}

Since the opening of the first year of internet public opinion in 2003, the internet has been widely involved in social politics and public life and played an unprecedented role. And the public opinion of the internet has received widespread attention from decision-makers down to the public. After four decades of continuous transformation, China's reform and opening-up has come to a critical stage, at which time it is very important to push forward the modernization of the national governance system and governance capacity. The first task of promoting national governance is to solve the public problems in the public domain and make the interconnected network space in an orderly state, and its goal of governance is to use public power, public resources and safeguard the public interest. At this time, the network development brought about by the "mass microphone era" has attracted the attention of the Party and the state, the main body of the network public opinion is diverse, rich in content, rapid dissemination and so on, which reshapes the traditional public decision-making information ecology [1]. It has become a new task to promote the work of national governance by studying and applying the public opinion of the network and giving full play to its role in public policy activities [2]. Therefore, as a new form of expression of transformation of China's social situation and public opinion, network public opinion has broken through the gradual process of traditional policy changes, and brought many new issues and even new problems to the theory and practice of public policy change.

\section{The Organic Fit of Network Public Opinion and Public Policy in Goal}

From the whole world modernization process, the realization of modernization is more and more focused on the overall public governance of the country, mainly manifested in the lack of public governance system and the strength of 
governance ability, which is the direction of the modernization of national governance. There is no doubt that public policy activities occupy the core and key position in the process of national public governance, and in the internet era, the network public opinion and public policy are closely related, so that in the new era of public policy formulation, implementation, adjustment and termination put forward higher requirements.

In practice, public policy is actually the concrete system design and arrangement to solve the contradiction between scarce public resources and growing public demand. And it is the sum of plans and actions led by public organizations, which focus on the use of public power, allocation of public resources, solving public problems and safeguarding public interests [3]. As an integral part of public opinion, the network public opinion refers to the public or collective with netizens as the main body, in a certain amount of time and network space, around a social phenomenon or social events and other intermediary stimulus matters, development and change of the object of social managers expressed and spread a certain intensity, tendency and influence of a variety of different emotions, wishes, attitudes, opinions and requirements and the sum and performance. The trigger mechanism of network public opinion is closely related to the public interest, its goal is to safeguard its own rights and interests, at the same time, public policy is the Party and the state in a certain historical period to solve a public problem or achieve a certain public interest to develop the norms of behavior and action norms. Its goal is to realize the public interest, which is the value orientation and logical starting point of public policy, and the essence and attribution of public policy, the starting point and the ultimate goal. Therefore, the network public opinion and public policy in the target positioning has obvious fit, the public opinion reflected in the network public opinion is the main body of policy to make public policy must consider the important content, the public based on this influence to form an attitude towards the government and public policy, and through the network public opinion reflected [4].

\section{The Influence of Network Public Opinion on the Whole Process of Public Policy}

From the essence of public policy, it is the authoritative distribution of social value, but also the basis and goal of the activities of the state and government [5]. Therefore, citizen participation is not only the basic requirement of public policy, but also an indicator of the extent to which public policy represents public opinion. Although the current political system of our country presets the system of people's congress, and the system of political consultation and other kinds of institutional ways of public opinion expression, it connects the public with the public policy process. From the practical policy process, network technology has gradually become the preferred way for the public to express public opinion because of its advantages of information pluralism, form diversity and convenient interaction. In this way, the traditional "man and nature, man and man" main objective dualism of ontology, epistemology structure is broken, "the morphology environment" is introduced into people's field of understanding, the public in the relatively relaxed and free information release pattern to generate and aggregate policy aspirations and demands, thus forming a network of public opinion and linked with public policy activities. In recent years, as an independent expression of popular ideology, the influence of network public opinion on public policy has gradually run through the whole process, and has different effects in different stages [6].

\subsection{Network Public Opinion Affects the Formation of Policy Issues}

The formation and confirmation of policy problems is the starting point of the process of public policy formulation, and policy problems are formed by the transformation of social problems into public problems. Therefore, the process of analyzing the formation of policy problems is actually the process of analyzing the transformation of "social problems public problems - policy problems" [7]. As the expression of public opinion, emotion and attitude as a public opinion, emotion and attitude has the function of reflecting social reality, once there are major public problems, netizens are in various types of network space for self-expression and dialogue and communication, and gradually spread to a wider range, causing more public attention, stakeholders and non-related parties are involved in it, forming network public opinion. Thus, the diffusion effect of network public opinion promotes the transformation of social problems to public problems, and then enters the policy agenda as a public policy issue.

\subsection{Network Public Opinion Influences the Establishment of Policy Agenda}

The establishment of the policy agenda is a key step in the process of policy formulation and the first step in the policy process. Social public issues enter the scope of the policy system composed of the main body of policy action, and it is only after competition and consultation that it can be put on the policy agenda [8]. For public issues to be translated into public policy issues and at the forefront of government agendas, they need to be fully discussed, bringing together the sources of problems, political sources and policy sources, and promoting the opening of the "window of policies" in order to develop public policies that are in line with public opinion. As in 2003 the landmark event of the network public opinion "Sun Zhigang case" after the outbreak of a storm on the network, quickly led to the continuation of many years of "urban vagrants begging for shelter and removal measures" repeal. On the contrary, this case can be found that: the traditional one-way mode of information dissemination and the lack of wide range of public opinion, so that the construction of public policy problems is often based on the determination of the main body of policy-making, and the final formulation of public policy is also difficult to ensure 
that it meets the needs of the majority of members of society. Thus, the dissemination of information on the network and the expression of public opinion together form problem and political flows, and the various options formed in cyberspace can be seen as policy flows, which together can facilitate the opening of the "window of policy".

\subsection{The Planning of the Policy Plan of the Influence of Network Public Opinion}

When policy issues are brought to the attention of the Government and are on the policy agenda, the government will propose policy objectives and develop alternatives to the corresponding issues, and determine the best public policy through revision of the alternatives. The influence of network public opinion on the policy planning is mainly reflected in the design, revision and final choice of policy options. However, the design of alternatives is inevitable because of the limitations of the policy makers' own knowledge and abilities. And the popularity of the network so that thousands of public members are free to express their views on a public issue, thus forming a strong network public opinion. These network public opinions aggregate the policy proposals and interests of different groups, thus providing rich and diverse information for the planning of public policy programs, and becoming an important basis for the government to make the trade-offs and value choices of alternative policy options.

\subsection{The Regulation of the Influence of Network Public Opinion on the Implementation of the Policy}

Policy implementation is a key link in the life process of policy, playing an irreplaceable role in other links. As Allison puts it, "In meeting the government's goals, only 10 per cent of the functions identified by the programme are determined, while the remaining 90 per cent depends on effective implementation." Policy implementation has two analytical paths: "top-down" and "bottom-up" analysis methods. "Top-down" is the implementation process of the policy as a sequence of orders issued and passed layerby from the highest administrative body, which tends to take a negative view of the discretion of the executive body, which may be the cause of the deviation of the order in the execution. The bottom-up analysis path acknowledges that each organization and individual chooses to have a reason to act on its own. The emergence of network public opinion makes the "bottom-up" path more used in the process of policy implementation, in which a variety of wishes and attitudes collide and tend to view the "discretion" of the executive body in a neutral attitude, thus more adapted to the policy implementation analysis in the context of multiple participation.

\subsection{Feedback on the Policy Assessment of the Impact of Network Public Opinion}

According to E. S. Quaid, public policy assessment is a process analysis of value, but in the narrow sense it is investigating an ongoing plan to measure the difference between its actual and expected accomplishments. Since public policy is mainly to realize the interests of the majority, the participation and response of citizens in the process of designating policies is particularly important, and accordingly, the degree of citizen participation and response is also an important measure of the success of the policy. Therefore, as a part of the social situation and public opinion component, the development trend of the network public opinion has become an important plate that can not be ignored in the public policy evaluation. In this way, the network public opinion with the network as the carrier has brought about a change in the way of policy evaluation, forming a "responsive-constructive" evaluation method: mainly by listening to the different voices and feedback of the network public opinion, comprehensive analysis of the problem, full consideration of the actual situation, appropriate response to the public opinion, so that the analysis and evaluation of public policy links are strong and effective and accurate.

\section{The Blocking Effect of Network Public Opinion on the Public Policy Process}

Public policy as the authoritative distribution of social interests, public ity is its primary basic attribute, thus determining that public policy must and only reflect the interests of the majority of people have legitimacy. In the new media environment, the network public opinion is becoming more and more important to the policy agenda setting [9], although the emergence of the network has changed the traditional public policy-making process and the role of citizen participation, and has produced a new form of network democracy. However, the network public opinion is only the social relations and other "image" in the network, the current social reality in China has prompted the network public opinion response to show an increasingly complicated tendency. As far as the combination of network public opinion and public policy activities is concerned, there is inevitable a common obstacle between technical and political aspects throughout the process.

\subsection{Technical Delay Sabothers of Network Public Opinion}

First, Information overload. The rapid development of network information technology promotes the further modernization of society, mainly manifested in the omnipresent and massive existence of information. Barber expressed concern that "the problem in a modern democratic society is not that there is too little information, but too much information that can be obtained with little meaning". Barber is expressing the phenomenon of information overload in network democracy [10]. Indeed, policy formulation and consultation require a rational dialogue among the parties involved on the basis of a certain amount of information. The problem, however, is that when the total amount of information becomes more, its value density decreases accordingly. However, the public's attention as a social person is limited. Therefore, in the face of almost infinite expansion and fish and dragon mixed network information storm, it is 
difficult for people to fully control and effectively deal with, and even confused in the vast ocean of information, and ultimately will reduce the efficiency and quality of information expression. In addition, in terms of the policy process, the rapid ness of network communication accelerates the speed of information interaction between policy parties, in which case people are often eager to express their views, leaving time for each other to listen and reflect becomes very limited, which also creates a short-term information overload.

Second, Information alienation. The so-called alienation of information refers to the situation in which the information created by the person becomes the force of restricting and controlling the other person. The alienation of network information originates from the characteristics of network information production and dissemination. Because of the anonymity, openness and speed of network communication, the production and dissemination of all kinds of information become more convenient, which make all kinds of false and harmful information very easy to flood in cyberspace. Secondly, the network as a new thing, its own authoritative order has not yet taken shape, coupled with the reality of the authority of the lag intervention, resulting in the lack of information supervision and filtering mechanism, which is the network information alienation of the institutional background. The alienation of information will bring many negative effects first, to increase the cost of information screening and acquisition, reduce the efficiency of network consultation, second, to reverse the relationship between people and information, so that the network public is dominated by tool rationality, weakenthed the policy quality guided by public rationality, third, because the technical characteristics of the network make the network information manipulative, some profit-making groups control the voice by manipulating the dissemination of information or even distorting or falsifying information, thus creating new inequalities.

Third, The information gap. The information gap reflects the uneven distribution or distribution of information. There are many reasons for the existence of the information gap, both objective and citizens themselves. From the objective conditions, due to the existence of urban-rural dual structure and the implementation of the unbalanced development strategy after the reform and opening-up, the economic development of various places is uneven. Some rural and remote areas are unable to access the internet because of weak economic bases, lack of knowledge and talent, inadequate infrastructure construction such as information networks, and inability to access the internet. At the same time, there is a "gap" in the real society behind the information gap, and behind digital inequality is the inequality of economic status. From the citizen's own point of view, the economic situation is an important factor affecting its ability to use the network, but also affectthet network use and information access and enjoyment of the "rich and poor problem", forming the so-called "network nobles", and divide the information rich and information poor. The existence of the information divide creates a number of technical barriers in front of citizens, and equal rights and opportunities for participation are impossible for many citizens. As a result, the inclusiveness of online public opinion has become more limited, with the information rich having and controlling a large amount of information that can effectively participate in and influence the policy-making process.

\subsection{Political Blocking Caused by Network Public Opinion}

Firstly, Collaborative filtering leads to the Balkanization of public opinion and affects the breadth of public opinion expression. The formation of public opinion must first ensure that the public can enjoy comprehensive and diverse information, and on the basis of having a certain degree of common experience, the collision of different opinions and suggestions through public forums, and then form consensus. In the age of the Internet, the public has gained the power to filter information indefinitely, changing the one-line, top-down process of transmission, as Schramm claims: "The days of being called mass media and tiny individuals seem to be approaching intermediaries." The media is finally no longer so unengageable and inexplicable. And "My Daily" is moving to reality. At the same time, because the network gives the public the freedom to cut and filter information, so that the network public opinion shows the phenomenon of information narrowing. In other words, in different cultural contexts, individuals in cyberspace tend to prioritize views that are consistent or similar to themselves, and reject ideas that are at odds with or from themselves, thus limiting the breadth of public opinion expression. Thus, the expression of public opinion in the network space appears "network public opinion Balkanization", meaning that the formation of one isolated and divided group, by "countless 'my daily newspapers' to dominate the market, will not be conducive to the promotion of autonomy."

Secondly, the limited and out-of-order expression of public opinion affects the depth of public opinion expression. The quality of network public opinion is mainly influenced by the situation of network political participation. The expression of network public opinion is a new form of political participation in the new period, and network participation can be divided into social participation, economic participation and political participation. Research on participation usually has a preconception: with the spread of the Internet, more and more people are participating in network activities, the frequency of participation in the network is getting higher, and the level and ability of citizens as a whole to participate in network politics will be increased accordingly [11]. This causality is too far-fetched, network society, economic participation does not mean or even directly affect the network political participation. For example, we don't think that buying behavior like online shopping can lead to a rise in personal political literacy. Therefore, the online political participation behavior of netizens is always limited. In addition, because of its hidden and virtual characteristics, the network easily leads to the prevalence of irrational public opinion expression behavior, showing the disorder of political participation. The formulation of fair and reasonable public policy will inevitably require extensive public opinion expression and 
rational dialogue, and when the network public space is full of irrational discourse and extreme views, it will inevitably cause the obstruction of public opinion expression and hinder the whole public policy activity.

Thirdly, The post-lag effect of policy precipitation affects the rational ecology of public opinion expression. When he was an administrator, the ancient Roman historian Tassie once talked about the feeling of governing: when the government is unpopular, both good and bad policies offend the people. This insight later became the famous "Tassie Trap" law in Western political science. In the internet age, the "Tassie Trap" is hidden in every public opinion hot spot event like a spell. The relevant departments to deal with the incident or deal with a little careless, it is possible to fall into the "Tassie trap", so that people will public behavior, market behavior and personal behavior caused by the problems are habitually attributed to the government, this phenomenon is more or less caused by the past "policy precipitation". "Policy precipitation" is the residue of a certain period of policy, is the potential impact of the early policy results on the follow-up policy or positive and negative effects. Policy precipitation is objective, static under the incubation period. The stimulus of the new policy could shift it from a potential state to a active state. "Policy precipitation" is accumulated in the form of experience for netizens, through policy cognitive determination to their policy attitude, coupled with the individual selectivity of netizens cognitive model, affecting the rational ecology of public opinion, showing a certain irrational state.

Of course, the enthusiasm of citizen participation network to express public opinion also depends on the citizen's sense of self-efficacy of network participation. In Habermas's view, the effective functioning of public policy requires the process of forming public opinion through a dual track, that is, civil liberties dialogue, and conveying to decision makers and shaping policies, transforming "the power of public opinion into the power of administration". Obviously, the results of the expression of public opinion on the Internet must also be accepted in the political field of the country in order to have an impact and achieve practical results. The reality, however, is that the public is passionately engaged in the Internet, but the political system has been slow to enter, turning the original public-political-political-to-two-person dance into a self-indulgent solo dance. The political system's lagging or even negative response to the public opinion of the network will inevitably reduce the correlation between public opinion and public policy, and lead to the public network participation to reduce the effectiveness of the network and even more serious habitual consultation apathy.

\section{Conclusion}

Network public opinion is developed in the overlapping relationship between the real society and the network society, in the state of the mutual structure of network facts and social facts [12]. We attach importance to and study the value of network public opinion in public policy activities, mainly because the network public opinion is the projection of public social attitude, orientation and evaluation results on the network in the context of social development, and is the discourse expression of different social groups, class interests and social needs on the network. As public opinion is the most important basis of public decision-making, the network public opinion has the characteristics of faster response and wider reflection, it can carry out multiple rounds of discussion, more realistic feedback to the network public opinion to the policy subject, which just makes up for the shortcomings of the traditional media reflectthe on public opinion, and becomes a new carrier of the orderly increment of citizen's policy participation [13]. However, the network public opinion inevitably has a blocking effect on the pursuit of the public interest of the essence of public policy, so the network can not become an alternative way of public opinion expression, but should be a supplement to many institutionalized expressions in our country's political system [14]. In order to achieve this functional positioning, in the face of network public opinion information can usually spread widely in a very short period of time, the effective disposal of network public opinion is bound to face greater adjustment, so the government needs to adjust and change the policy of response to network participation [15], make full use of the positive utility of the technical carrier of network public opinion, make up for the omission and lack of public opinion expression in the real world, so that the discussion of policy issues can realize the seamless connection between the Internet and the network, improve the public policy system's perception of public opinion and the response.

In order for public policy to effectively enhance people's livelihood and meet the needs of the public, a democratic society needs a smooth way of public opinion expression, which can provide the possibility for the realization of the public discourse of different social strata and groups, so that different policy views can be presented, so that the policy debate can be carried out smoothly. Although the network has become the most popular way of public opinion expression of our country's public, the function and value of the network public opinion can be highlighted. But netizens can not be equated with citizens, not to mention active citizens, the network can not solve the plight of public opinion expression, the network public opinion expression can not replace or replace other ways, but should be a supplement. Therefore, in the process of public policy activities, we need to make full use of the function of traditional pre-set ways, focus on grasping the network public opinion occurrence, development law on the basis of better carrying out the network public opinion response work, pay attention to the network public opinion guidance and control [16], eliminate the negative impact of bad network public opinion information, and then give full play to the positive effect of good network public opinion, so that it can give full play to the function of carrying public opinion, promote social progress, and strengthen the complementary role of network public opinion, so as to balance the needs of all aspects of the interests. Making policy subjects work out "Pareto's best" public policy. 


\section{References}

[1] Yan Chen, The Theory and Practice of Network Public Opinion, Hubei Education Press, 2017, 88.

[2] Wang Guohua and Zeng Runxi and Fang Fujian, Decoding the public opinion of the network, Huazhong University of Science and Technology Press, 2014, 162.

[3] Yan Qiang, The Course of Social Transformation and the Evolution of Policy Paradigm, Nanjing Social Science, 2007, 5.

[4] Zhang Xiaoming, The Problems and Challenges of China's Public Policy Input, China Administration, 2013, 7.

[5] Yan Qiang, The Modernization of National Governance and the Choice of The Paradigm of Public Policy Research, Jianghai Journal, 2014, 1.

[6] Wan Xuanao and Xie Gengyun, Study on the Influence of Network Public Opinion Spread on Public Policy, Friends of the Editor, 2015, 8.

[7] Zhu Min and Fan Bo, Study on the agenda setting of network public opinion governance, Administrative Forum, 2017, 6.

[8] Wan Xuanao, Network Public Opinion Spread and the setting of China's public policy agenda, New Media and Society, 2018, 4.

[9] Lu Yanqing and Zhao Jianguo, Research on the policy-setting agenda of network public opinion based on new media--taking multi-source flow theory as the perspective, E-government, 2018, 3 .

[10] Huang Yang and Li Weiquan, The Influence of Network Public Opinion on Policy Interruption Change in the New Media Environment: Based on the Perspective and Case Analysis of "Intermittent-Equilibrium Theory", E-government, 2018, 9.

[11] He Zhiwu and Chen cheng, Network Public Opinion Analysis under the Field of Public Decision: Subjectivity, Science and Tendency, E-government, 2020, 2.

[12] Yang Minggang, Network Public Opinion in the Age of Big Data, Haitian Press, 2017, 53.

[13] Zhang Yu, Network Media: A New Carrier of Citizen Policy Participation in The Order Increment, Party and government research, 2015, 6 .

[14] Chen Rui, The role and evolution of citizen participation in the process of public policy formulation since the reform and opening-up, Theory, 2014, 12.

[15] Wang Fashuo, Government's Response to The Change of Action in Network Participation, E-government, 2013, 3.

[16] Sheng Mingke and Shao Mengjie, The Dual Influence of Network Public Opinion on Public Decision-making, Gansu Social Science, 2014, 4. 